\title{
Nanomaterial-Facilitated Cyclin Dependent Kinase 7 Inhibition Suppresses Gallbladder Cancer Progression via Targeting Transcriptional Addiction
}

Chen-Song Huang ${ }^{l \#}$, Qiong-Cong Xu ${ }^{l \#}$, Chunlei Dai ${ }^{2 \#}$, Liying Wang ${ }^{2 \#}$, Yi-Chih Tien ${ }^{l}$, Fuxi Li ${ }^{3}$, Qiao Su${ }^{4}$, Xi-Tai Huang ${ }^{1}$, Jun Wu ${ }^{2 *}$,Wei Zhao ${ }^{3 *}$ and Xiao-Yu Yin ${ }^{1 *}$

\section{Contents}

Supplemental Figure 1-14

Supplemental Table 1 

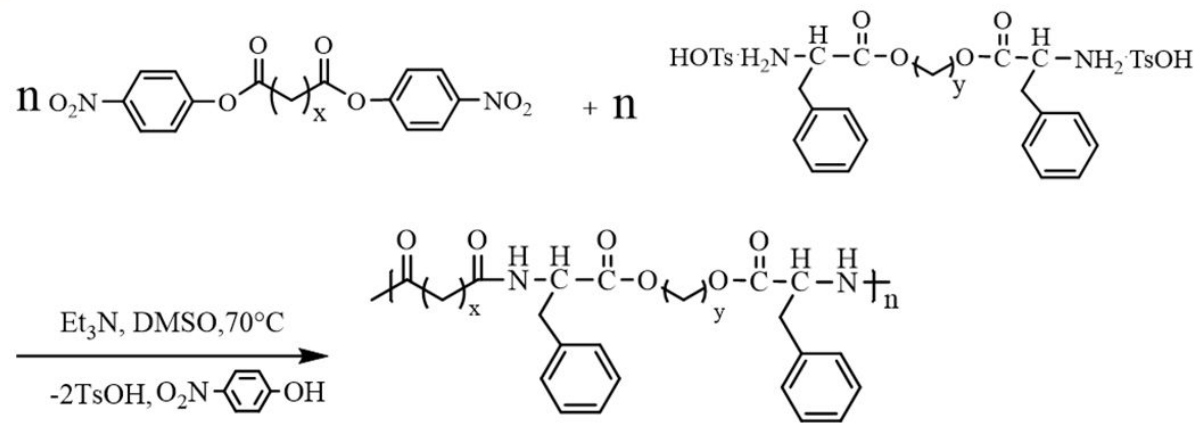

Figure S1. The synthetic route of 8-Phe-4 (8P4) polymer. 
A
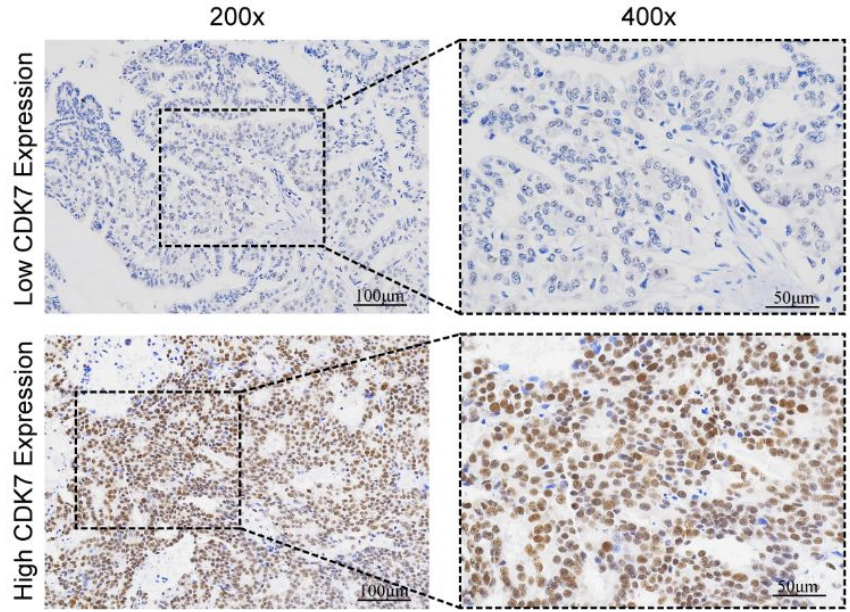

B

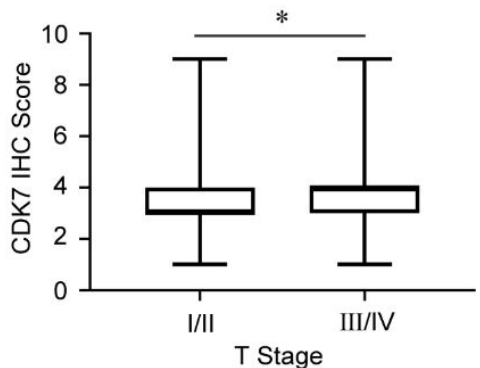

Figure S2. CDK7 is correlated with poor prognosis in human GBC.

A. Representative images of low or high expression of CDK7 in $\mathrm{GBC}$, as determined by IHC.

B. CDK7 expression in different T stages (stage I/II vs. III/IV) of GBC. 
A

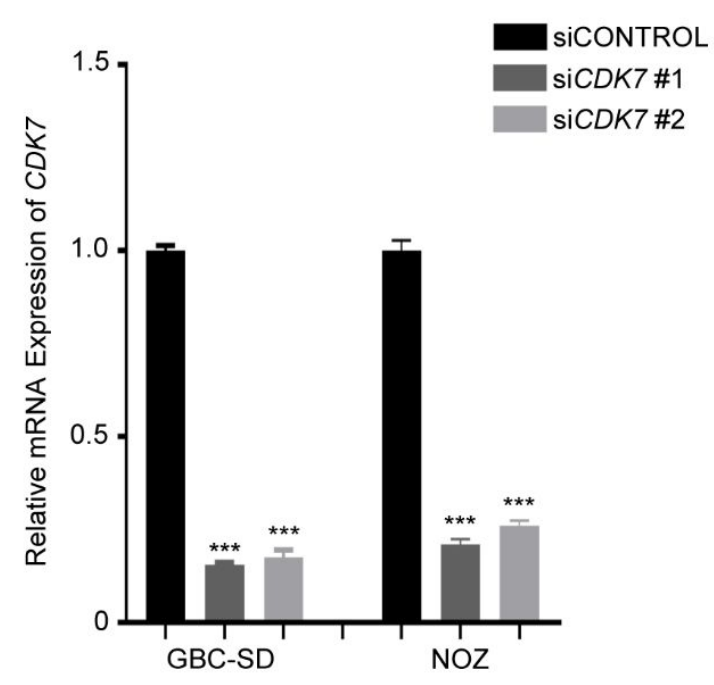

B

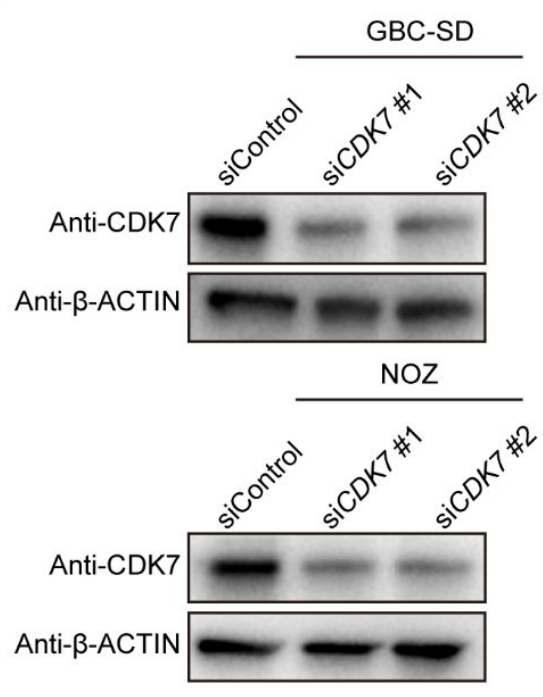

Figure S3. The CDK7 expression was silenced by the CDK7 siRNA.

A. The $C D K 7$ mRNA levels in GBC-SD and NOZ cells were measured by qRT-PCR after $C D K 7$ knockdown using siRNA.

B. The CDK7 protein levels in GBC-SD and NOZ cells were measured by western blotting after $C D K 7$ knockdown using siRNA. 
A
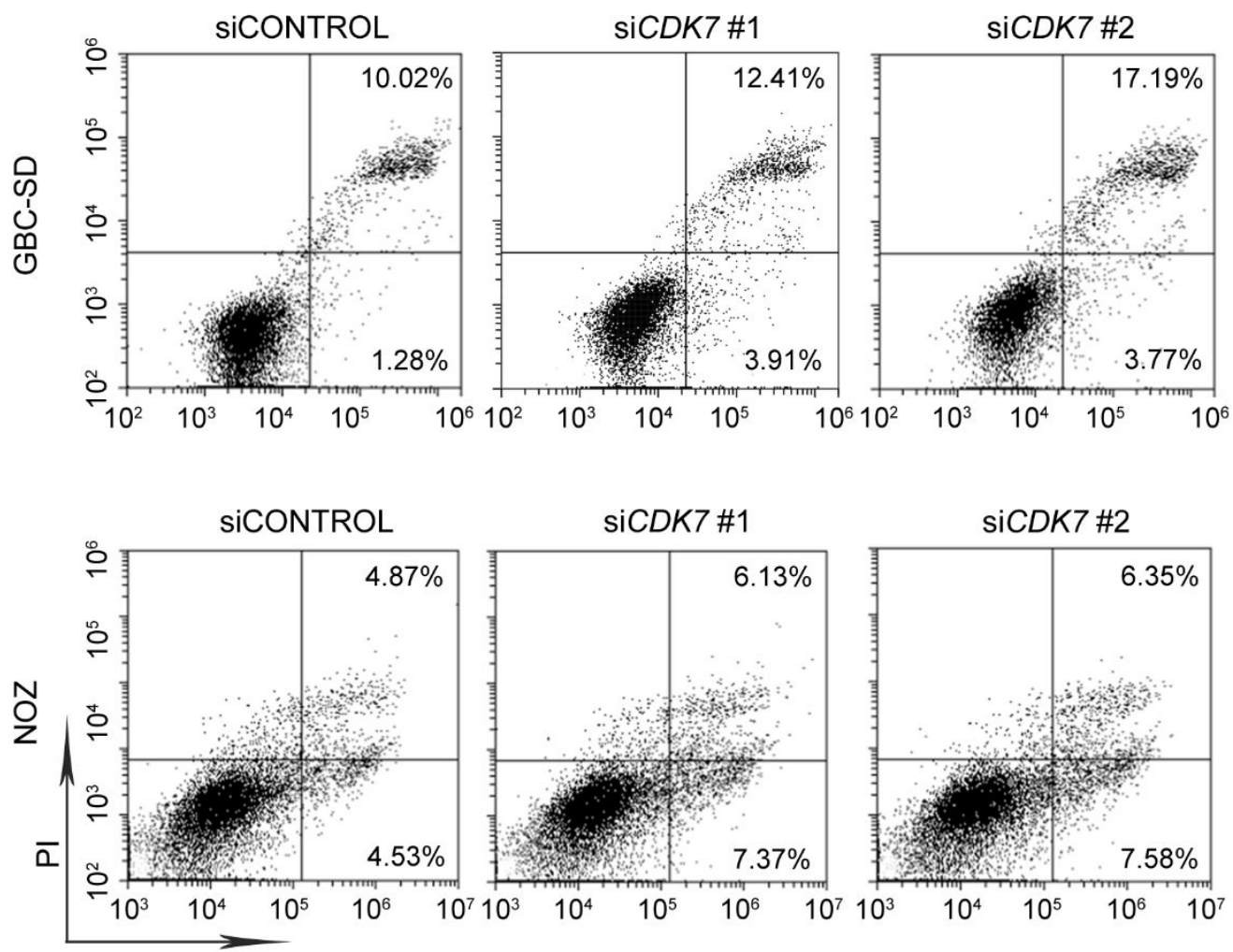

Annexin V-FITC

B
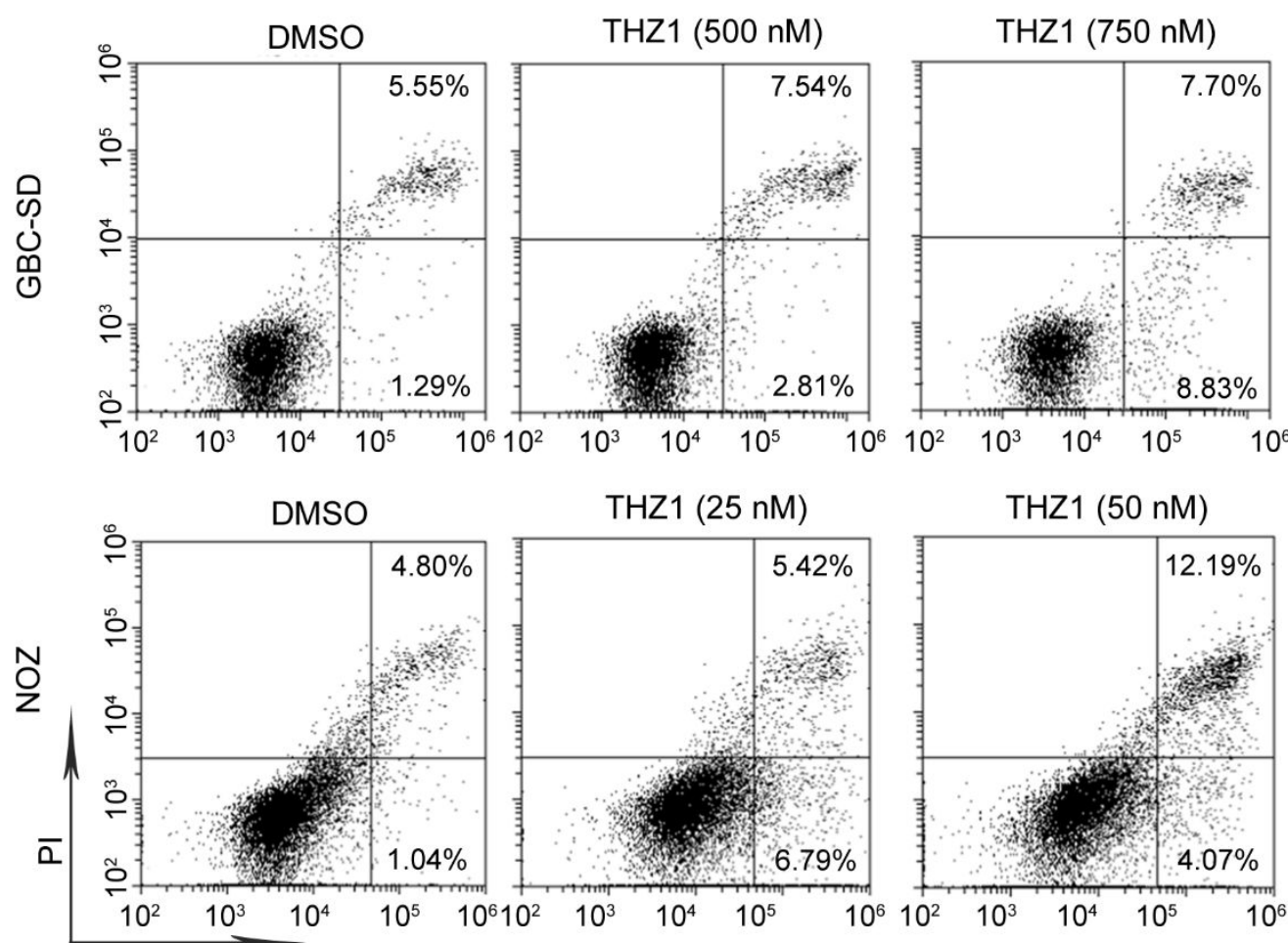

Annexin V-FITC

Figure S4. Inhibition of CDK7 promoted apoptosis in GBC.

A. Representative flow cytometry data of apoptosis analysis of GBC-SD or NOZ cells 
following $C D K 7$ siRNA transfection for $48 \mathrm{~h}$.

B. Representative flow cytometry data of apoptosis analysis of GBC-SD or NOZ cells treated with different concentrations of THZ1 or DMSO for $48 \mathrm{~h}$. 

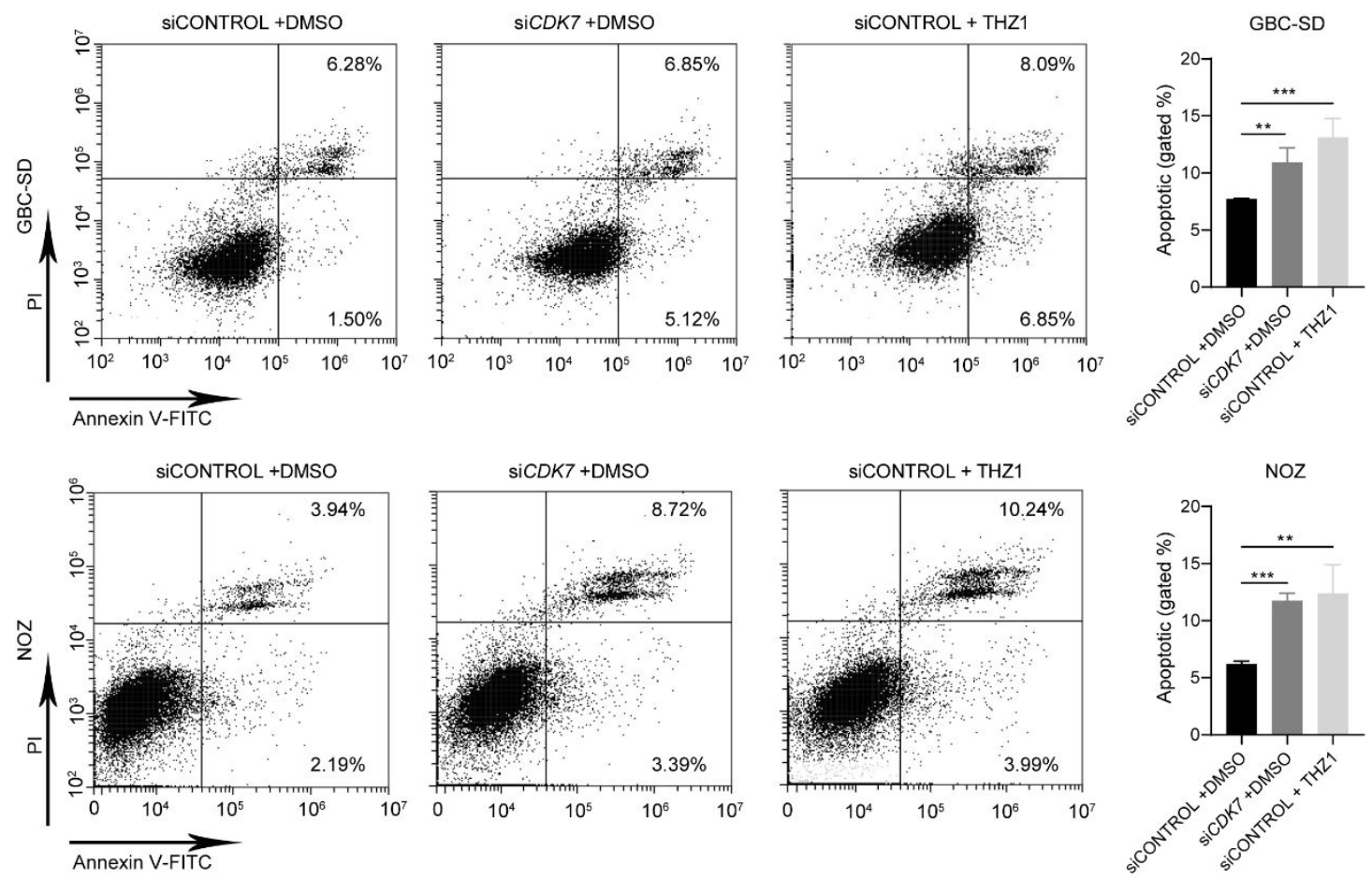

Figure S5. Apoptosis analysis of GBC-SD and NOZ cells treated with siCONTROL+DMSO, siCDK7+DMSO, or siCONTROL+THZ1 for $48 \mathrm{~h}$. 

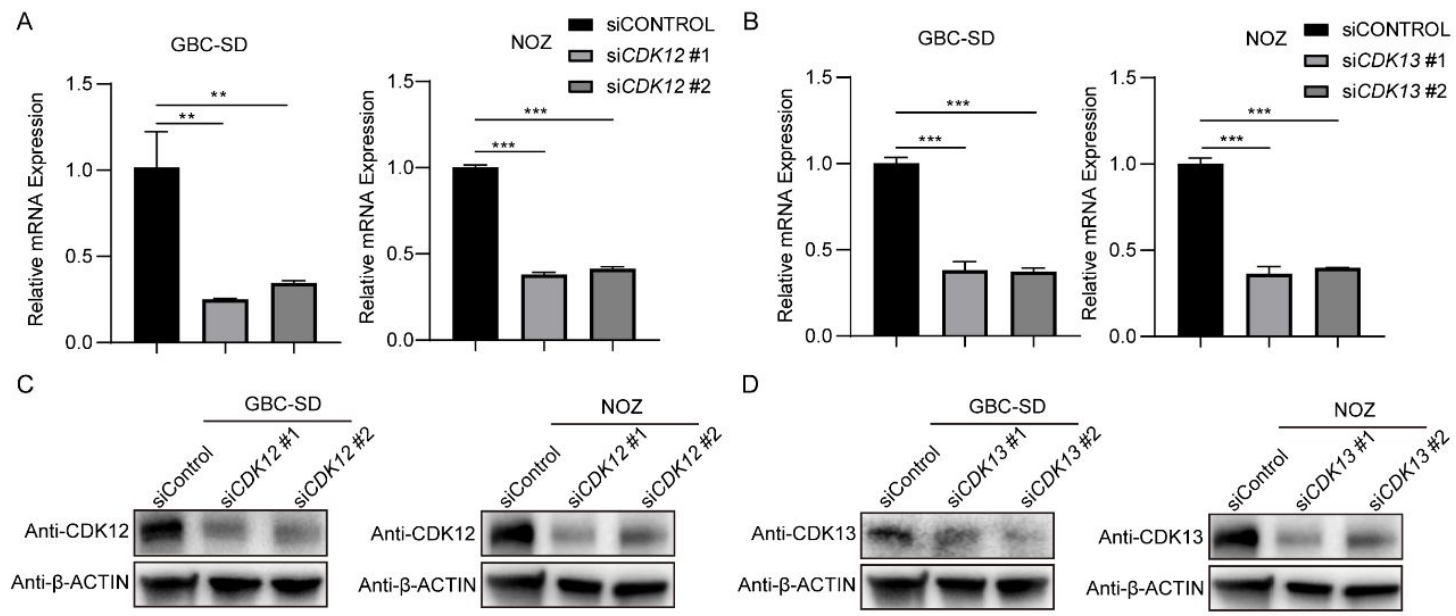

D
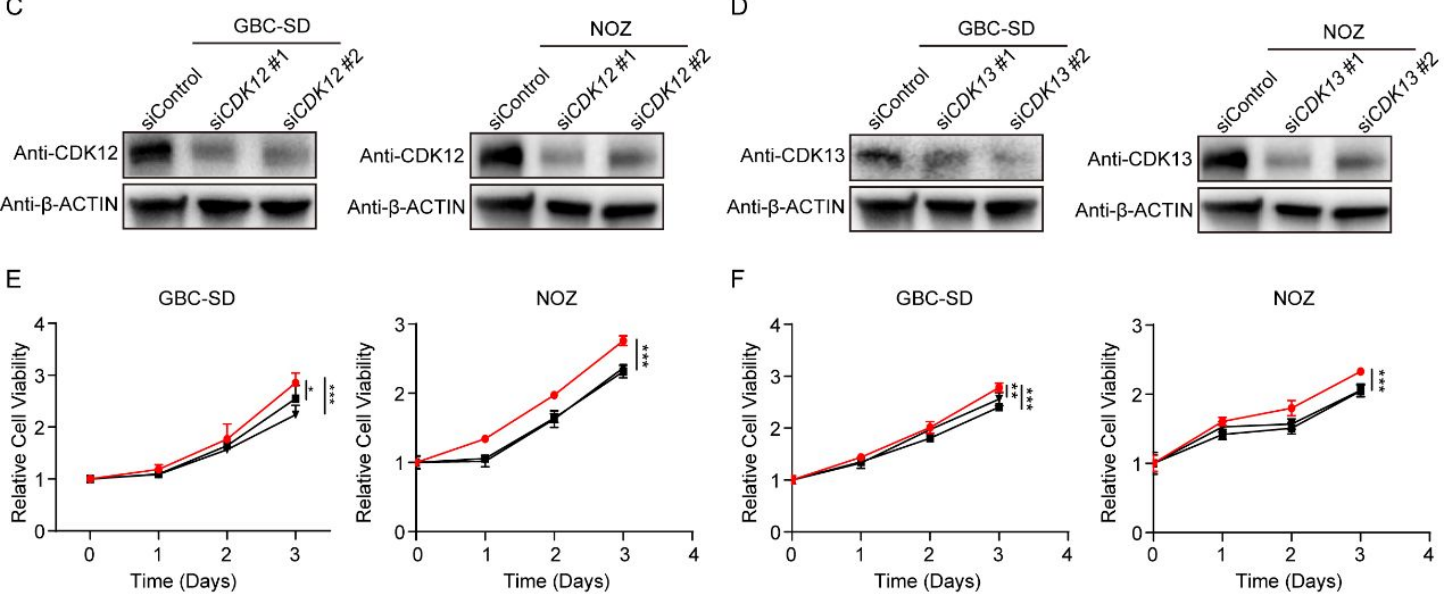

F
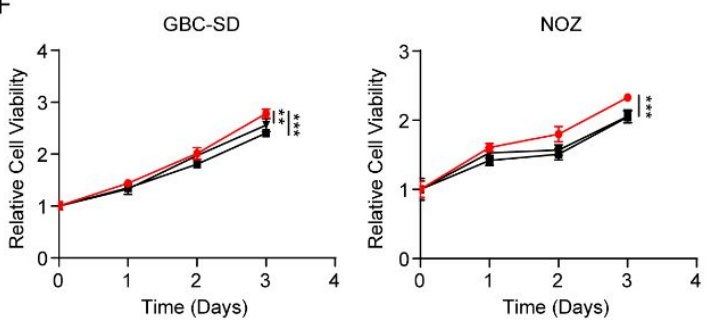

G

- siCONTROL - siCDK12\#1 * siCDK12\#2
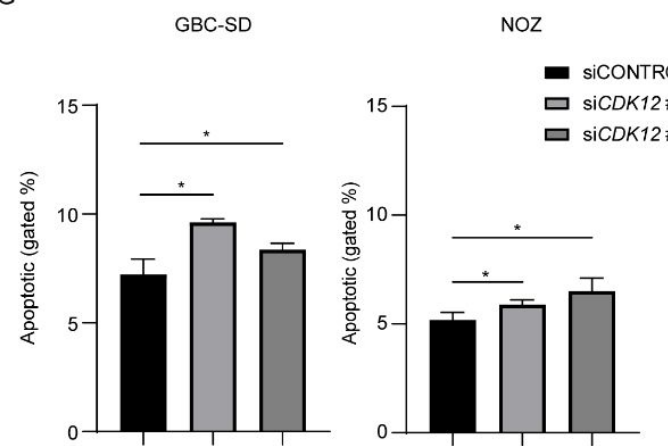

$\mathrm{H}$

- siCONTROL - $\operatorname{siCDK13\# 1~-~siCDK13\# 2~}$

GBC-SD

NOZ

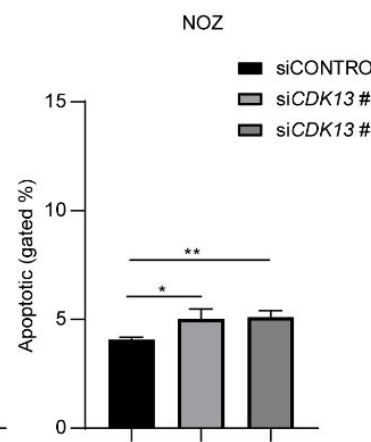

GBC-SD

NOZ

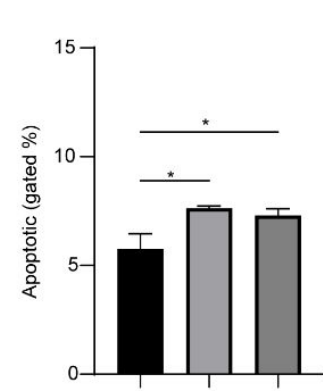

GBC-SD
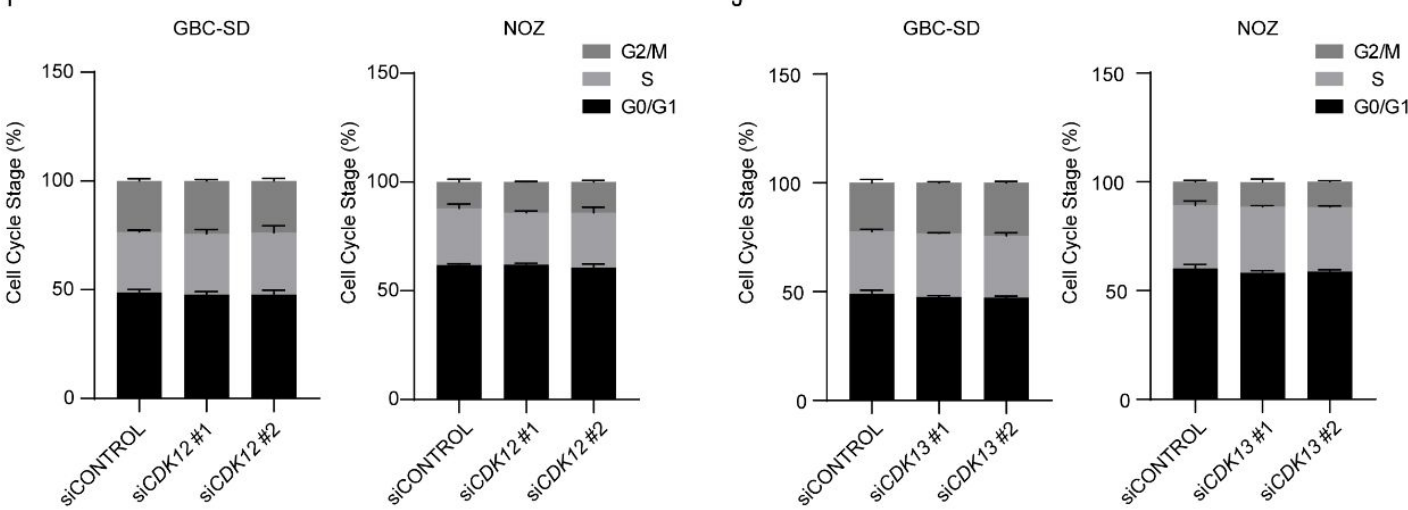

Figure S6. The effects of $C D K 12 / 13$ siRNAs on cell proliferation, apoptosis, and the cell cycle in GBC.

A. The mRNA expression of CDK12 in GBC-SD or NOZ cells transfected with or without $C D K 12$ siRNA for $48 \mathrm{~h}$. 
B. The mRNA expression of CDK13 in GBC-SD or NOZ cells transfected with or without $C D K 13$ siRNA for $48 \mathrm{~h}$.

C. The protein expression of CDK12 in GBC-SD or NOZ cells transfected with or without $C D K 12$ siRNA for $48 \mathrm{~h}$.

D. The protein expression of CDK13 in GBC-SD or NOZ cells transfected with or without $C D K 13$ siRNA for $48 \mathrm{~h}$.

E. Cell growth curve of GBC-SD and NOZ cells transfected with CDK12 siRNA or control.

F. Cell growth curve of GBC-SD and NOZ cells transfected with CDK13 siRNA or control.

G. Apoptosis analysis of GBC-SD and NOZ cells transfected with CDK12 siRNA or control for $48 \mathrm{~h}$.

H. Apoptosis analysis of GBC-SD and NOZ cells transfected with CDK13 siRNA or control for $48 \mathrm{~h}$.

I. Cell cycle analysis of GBC-SD and NOZ cells transfected with CDK12 siRNA or control for $48 \mathrm{~h}$.

J. Cell cycle analysis of GBC-SD and NOZ cells transfected with CDK13 siRNA or control for $48 \mathrm{~h}$.

The results are presented as mean $\pm \mathrm{SD}$ of three independent experiments. ${ }^{*} P<0.05$, ${ }^{* *} P<0.01, * * * P<0.001$, according to a Student's t-test. 
A
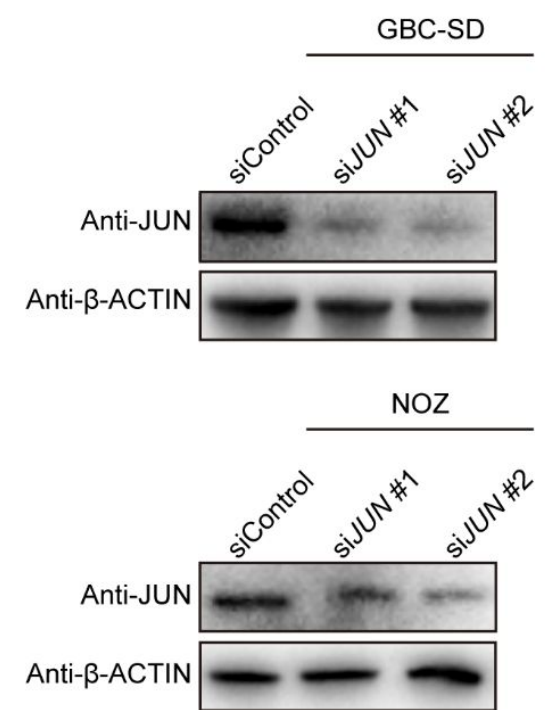

B
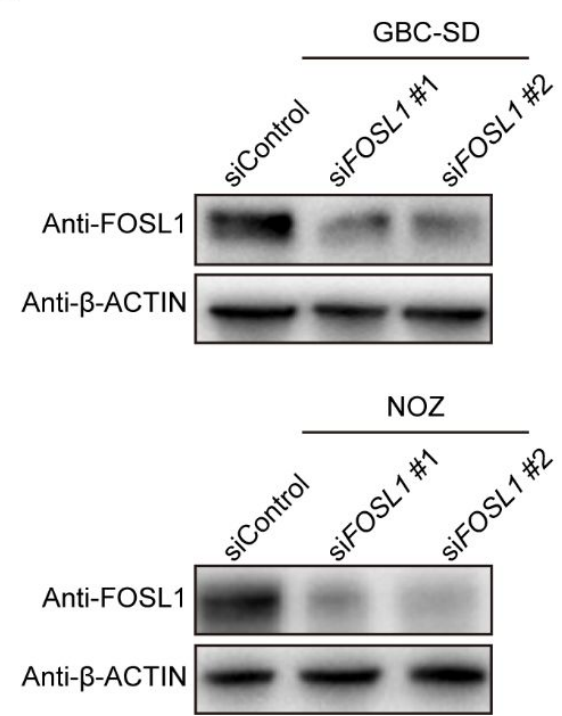

Figure S7. The JUN and FOSL1 expression were silenced by the JUN or FOSL1 SiRNA.

A. The JUN protein levels in GBC-SD and NOZ cells were measured by western blotting after $J U N$ knockdown using siRNA.

B. The FOSL1 protein levels in GBC-SD and NOZ cells were measured by western blotting after FOSL1 knockdown using siRNA. 
A

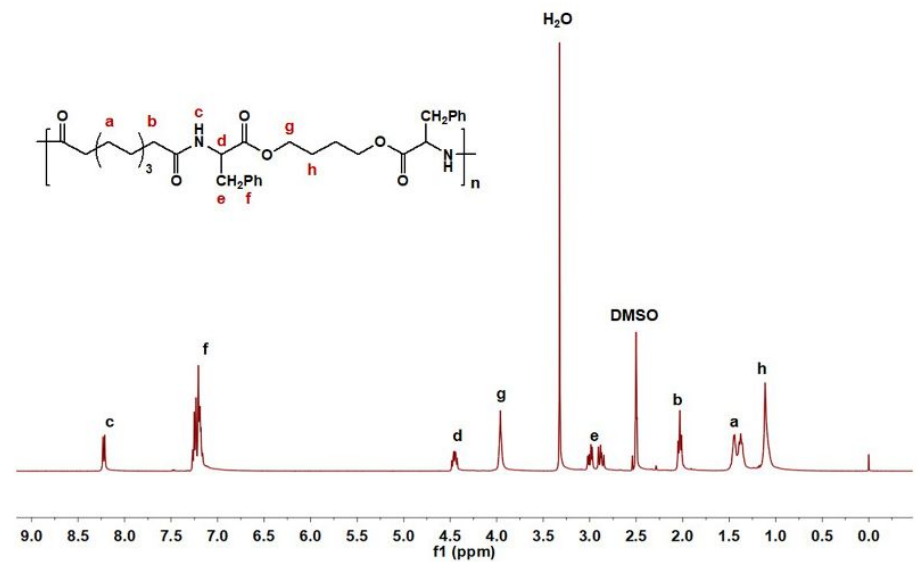

B

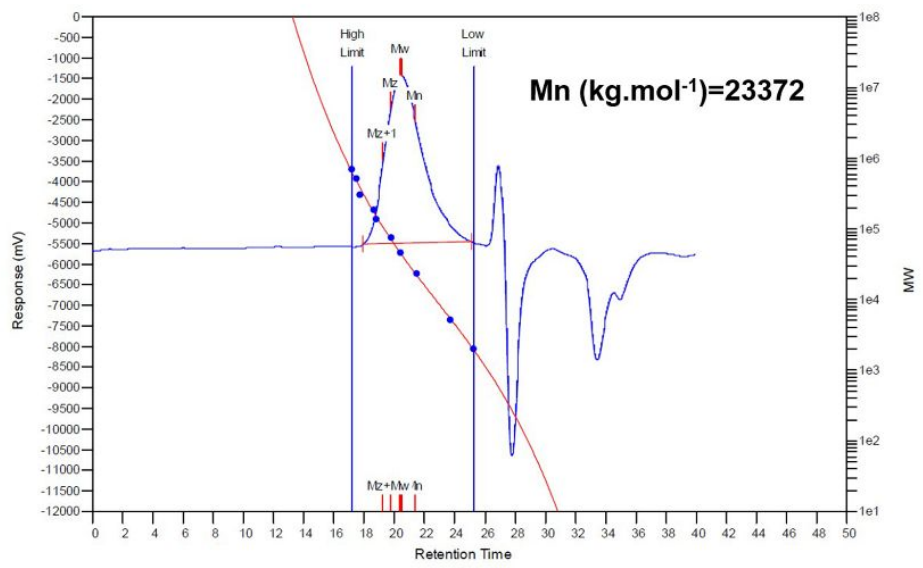

Figure S8. Characterization of 8P4 polymer.

A. ${ }^{1} \mathrm{H}$ nuclear magnetic resonance $\left({ }^{1} \mathrm{H} \mathrm{NMR}\right)$ of $8 \mathrm{P} 4$ polymer.

B. Gel permeation chromatography (GPC) spectrum of 8P4 polymer. 
A

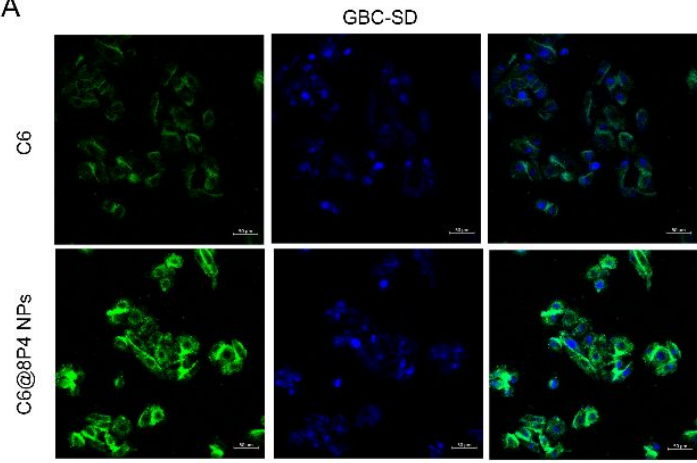

B

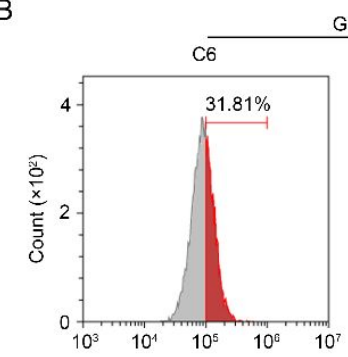

C

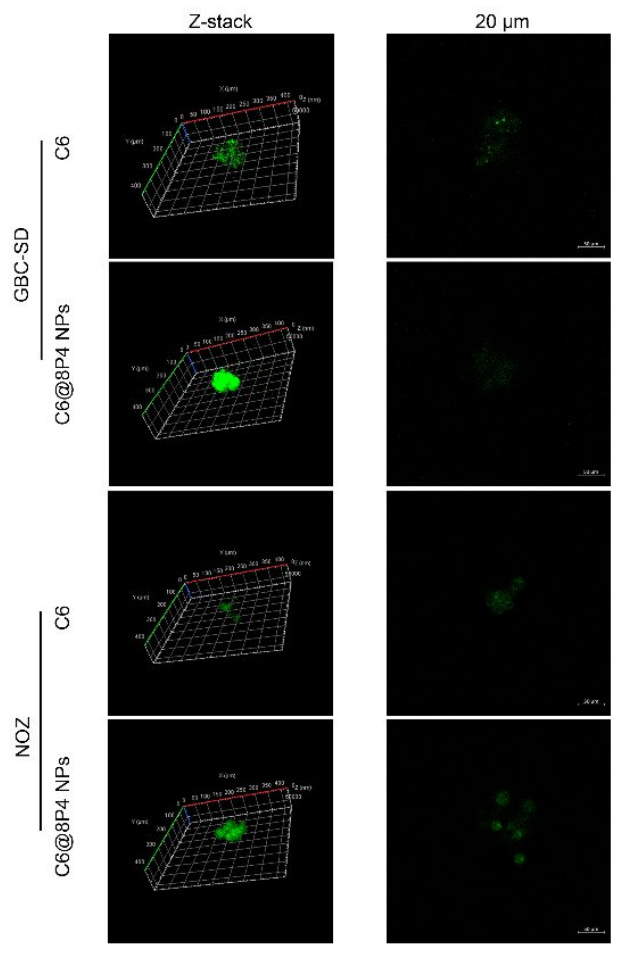

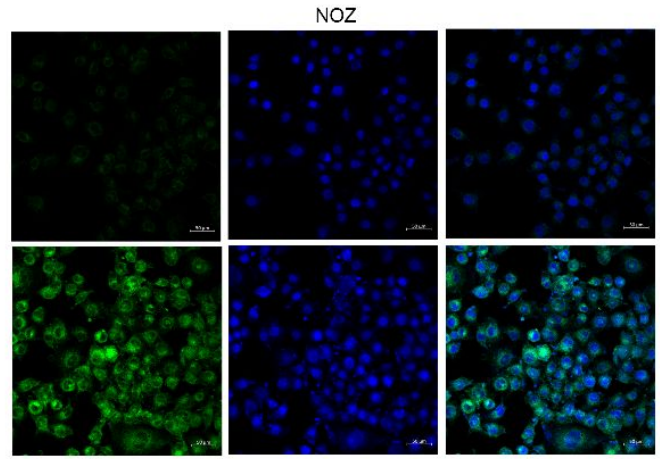

NOZ $\quad$ C6@8P4 NPs

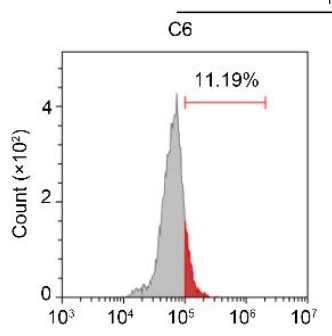

$40 \mu \mathrm{m}$
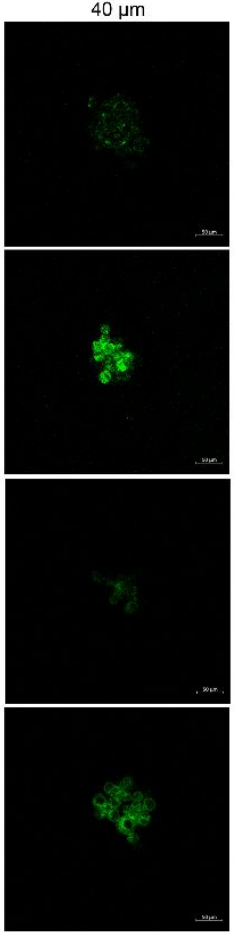

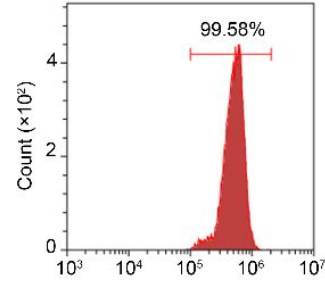

$60 \mu \mathrm{m}$
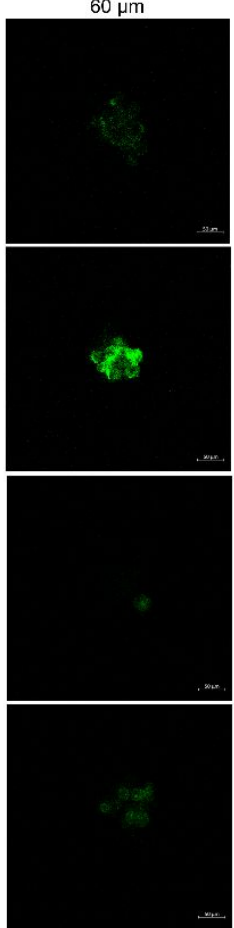

Figure S9. Cellular uptake behavior of C6@8P4 NPs in GBC cells.

A. Representative fluorescence images for the cellular uptake of Coumarin 6 (C6) or Coumarin 6-loaded 8P4 NPs (C6@8P4 NPs) in GBC-SD or NOZ cells after $24 \mathrm{~h}$ incubation. Scale bar $=10 \mu \mathrm{m}$.

B. Flow cytometry analysis of the fluorescence intensity of GBC-SD or NOZ cells treated with C6 or C6@8P4 NPs. 
C. Representative CLSM images of the cellular uptake of C6 or C6@8P4 NPs in GBCSD and NOZ tumor spheroids. Scale bar $=50 \mu \mathrm{m}$. 


$$
\text { (1) }
$$
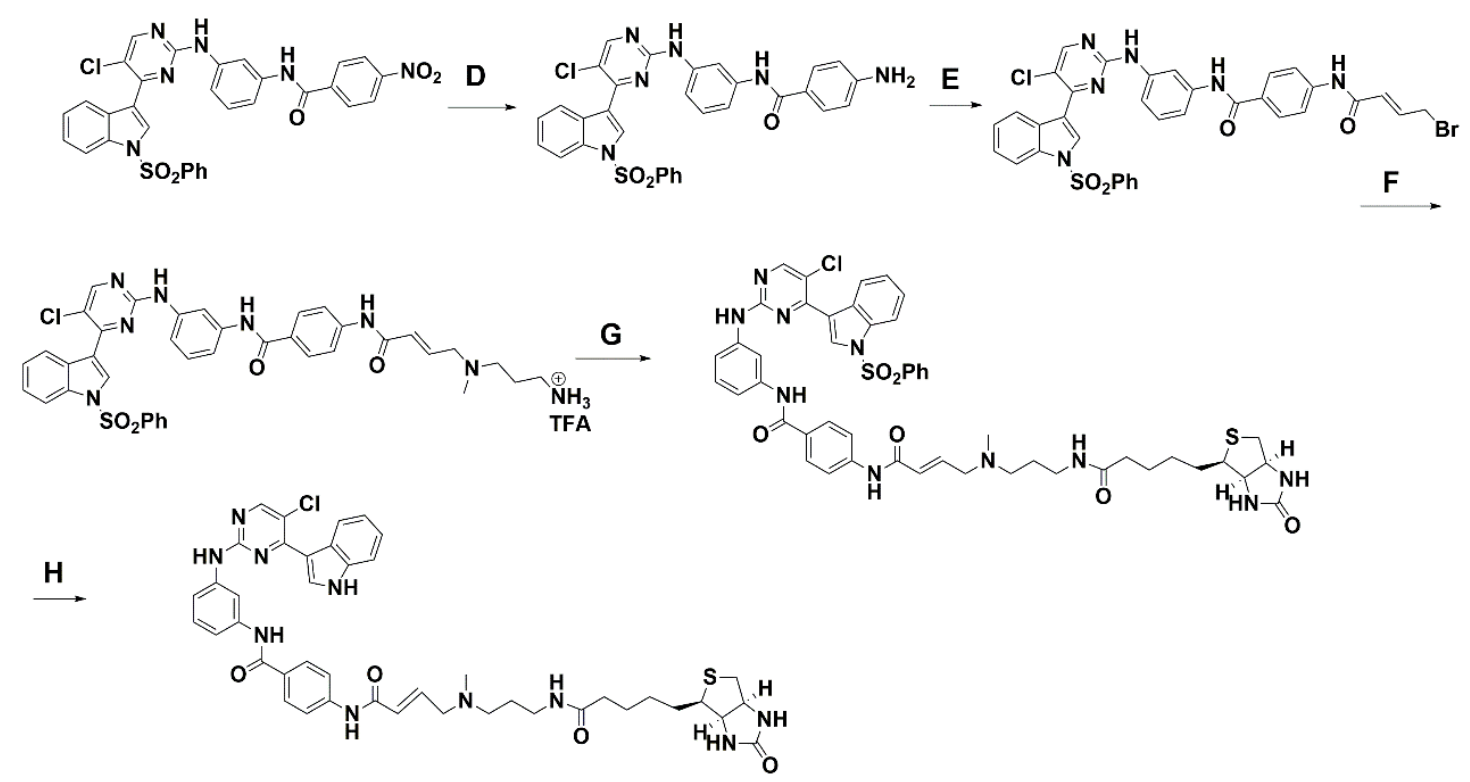

Figure S10. The synthetic route of bio-THZ1.

Reagents and conditions: A. $\mathrm{Pd}\left(\mathrm{Ph}_{3}\right)_{4}, \mathrm{Na}_{2} \mathrm{CO}_{3}, \mathrm{CHCN}, 75{ }^{\circ} \mathrm{C}$; B. NMP, 1,3phenylenediamine, $130{ }^{\circ} \mathrm{C}$; C. Et 3 N, DCM, $0{ }^{\circ} \mathrm{C}-\mathrm{RT}$; D. Fe, $\mathrm{NH}_{4} \mathrm{Cl}, \mathrm{H}_{2} \mathrm{O}$; $\mathrm{MeOH}, 0{ }^{\circ} \mathrm{C}-$ $80^{\circ} \mathrm{C}$; E. 1. (E)-4-bromobut-2-enoic acid, oxalyl chloride, DCM; 2. DCM, Et 3 N, $0{ }^{\circ} \mathrm{C}$ RT; F. 1. tert-Butyl (3-(methylamino.propyl)carbamatepiperidine, $\mathrm{K}_{2} \mathrm{CO}_{3}, \mathrm{KI}, \mathrm{DMF}$, $35^{\circ} \mathrm{C}$; 2. DCM,TFA; G. HATU, DMF, Et ${ }_{3} \mathrm{~N} ; \mathrm{H}$. NaOH, $\mathrm{H}_{2} \mathrm{O}$, Dioxane, $35^{\circ} \mathrm{C}$. 
A

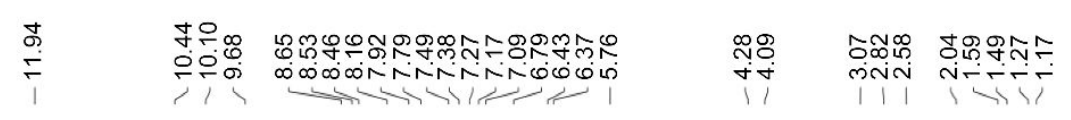
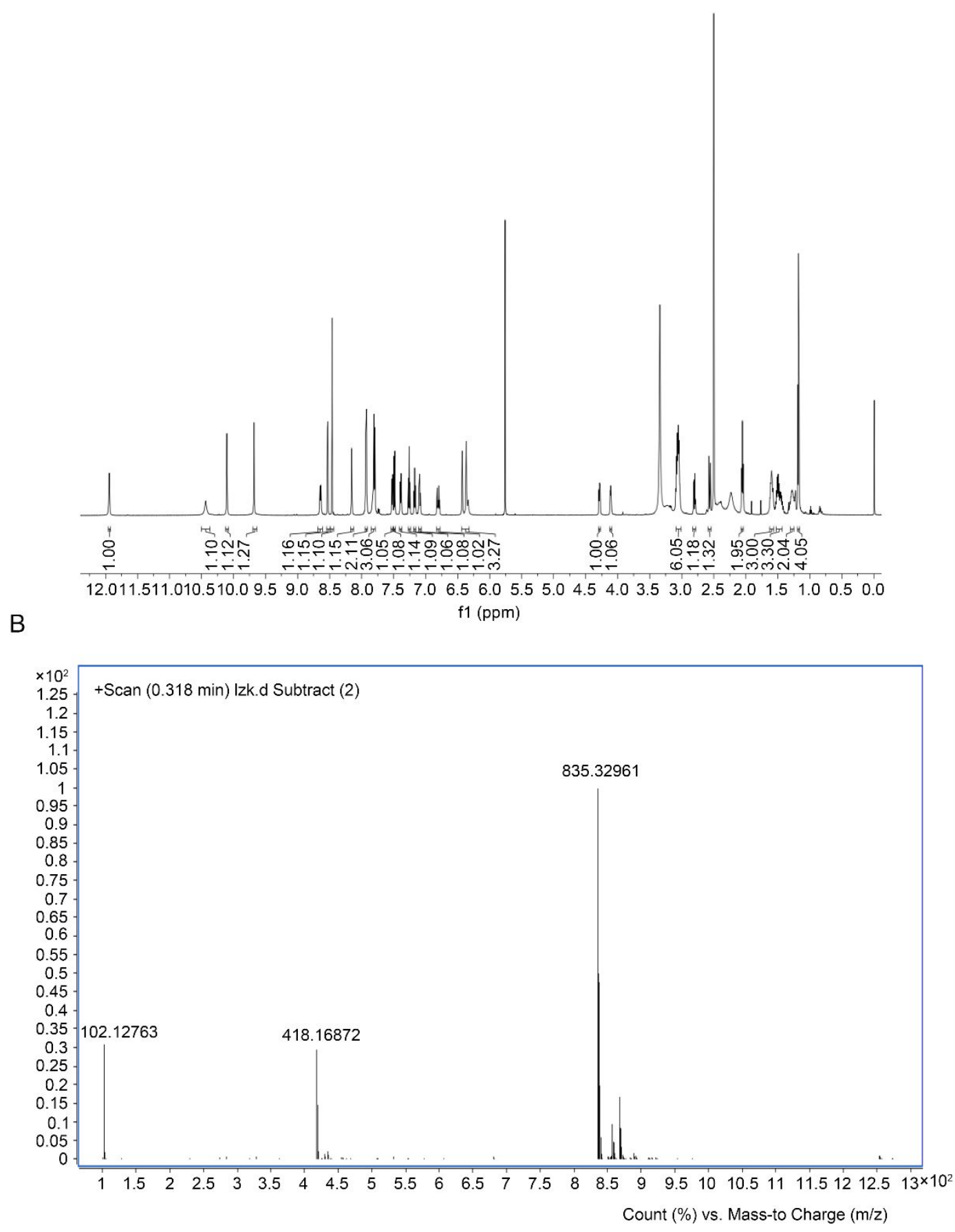

Figure S11. Characterization of bio-THZ1.

A. ${ }^{1} \mathrm{H}$ NMR of bio-THZ1. ${ }^{1} \mathrm{H}$ NMR (600 MHz, DMSO) $\delta 11.94(\mathrm{~d}, J=2.1 \mathrm{~Hz}, 1 \mathrm{H})$, $10.44(\mathrm{~s}, 1 \mathrm{H}), 10.10(\mathrm{~s}, 1 \mathrm{H}), 9.68(\mathrm{~s}, 1 \mathrm{H}), 8.65(\mathrm{~d}, J=7.9 \mathrm{~Hz}, 1 \mathrm{H}), 8.53(\mathrm{~d}, J=3.0 \mathrm{~Hz}$, 1H), $8.46(\mathrm{~s}, 1 \mathrm{H}), 8.16(\mathrm{~s}, 1 \mathrm{H}), 7.92(\mathrm{~d}, J=8.7 \mathrm{~Hz}, 2 \mathrm{H}), 7.82-7.79(\mathrm{~m}, 3 \mathrm{H}), 7.52(\mathrm{~d}, J$ 
$=8.0 \mathrm{~Hz}, 1 \mathrm{H}), 7.49(\mathrm{~d}, J=8.1 \mathrm{~Hz}, 1 \mathrm{H}), 7.38(\mathrm{~d}, J=8.7 \mathrm{~Hz}, 1 \mathrm{H}), 7.27$ (t, $J=8.1 \mathrm{~Hz}$, 1H), $7.17(\mathrm{t}, J=7.2 \mathrm{~Hz}, 1 \mathrm{H}), 7.09(\mathrm{t}, J=7.5 \mathrm{~Hz}, 1 \mathrm{H}), 6.83-6.79(\mathrm{~m}, 1 \mathrm{H}), 6.40(\mathrm{t}, J=$ $28.8 \mathrm{~Hz}, 3 \mathrm{H}), 4.30-4.28(\mathrm{~m}, 1 \mathrm{H}), 4.12-4.09(\mathrm{~m}, 1 \mathrm{H}), 3.07-3.03(\mathrm{~m}, 6 \mathrm{H}), 2.82-2.79(\mathrm{~m}$, 1H), 2.58 (d, $J=12.4 \mathrm{~Hz}, 1 \mathrm{H}), 2.04$ (t, $J=7.4 \mathrm{~Hz}, 2 \mathrm{H}), 1.61-1.59$ (m, 3H), $1.54-$ 1.49 (m, 3H), $1.33-1.27$ (m, 2H), 1.17 (t, $J=7.3 \mathrm{~Hz}, 4 \mathrm{H})$.

B. High resolution mass spectrum (HR-MS) of bio-THZ1, calcd for $[\mathrm{M}+1]=835.3291$, found 835.3296 . 
A
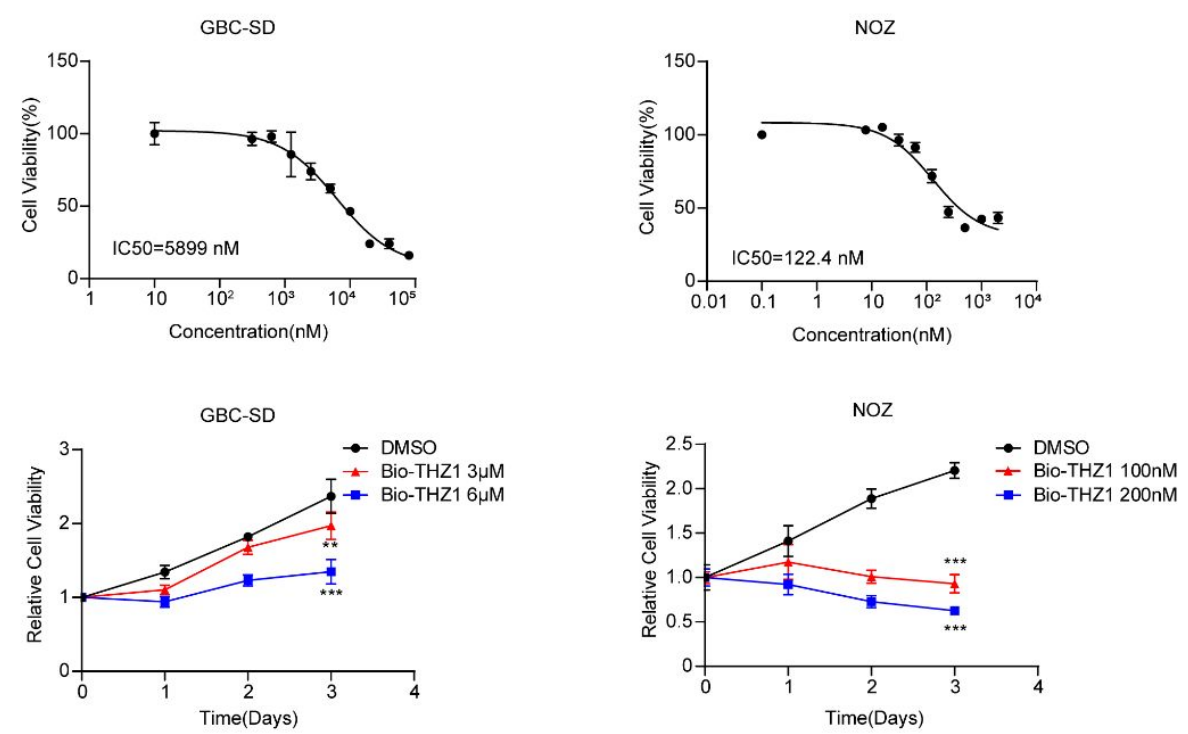

c
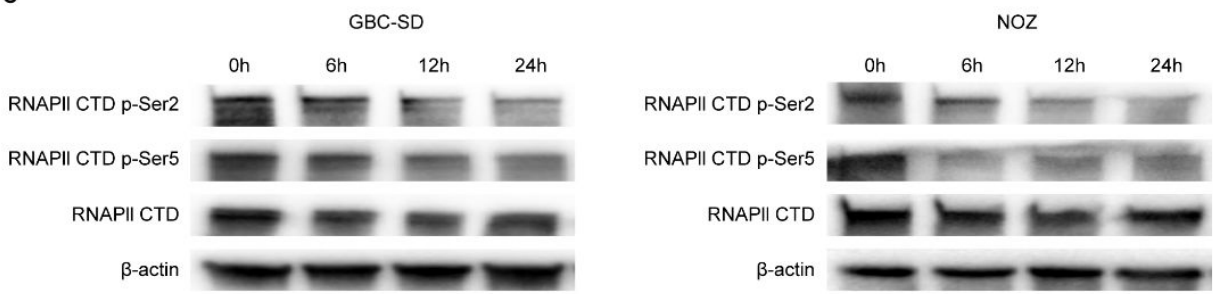

Figure S12: Biotin-THZ1 inhibited cell proliferation and RNAPII CTD phosphorylation in GBC.

A. GBC-SD and NOZ cells were treated with the indicated concentrations of biotinTHZ1 for $48 \mathrm{~h}$. Cell viability relative to that of DMSO-treated cells is shown.

B. GBC-SD and NOZ cells were treated with biotin-THZ1 at indicated concentration for $48 \mathrm{~h}$. The relative cell viability related to DMSO group was shown.

C. Immunoblotting analyses of phosphorylation of C-terminal repeat domain (CTD) of RNA Polymerase II (RNAPII) in GBC-SD and NOZ cells treated with biotin-THZ1 (6 $\mu \mathrm{M}$ and $200 \mathrm{nM}$, respectively) at different time points. 

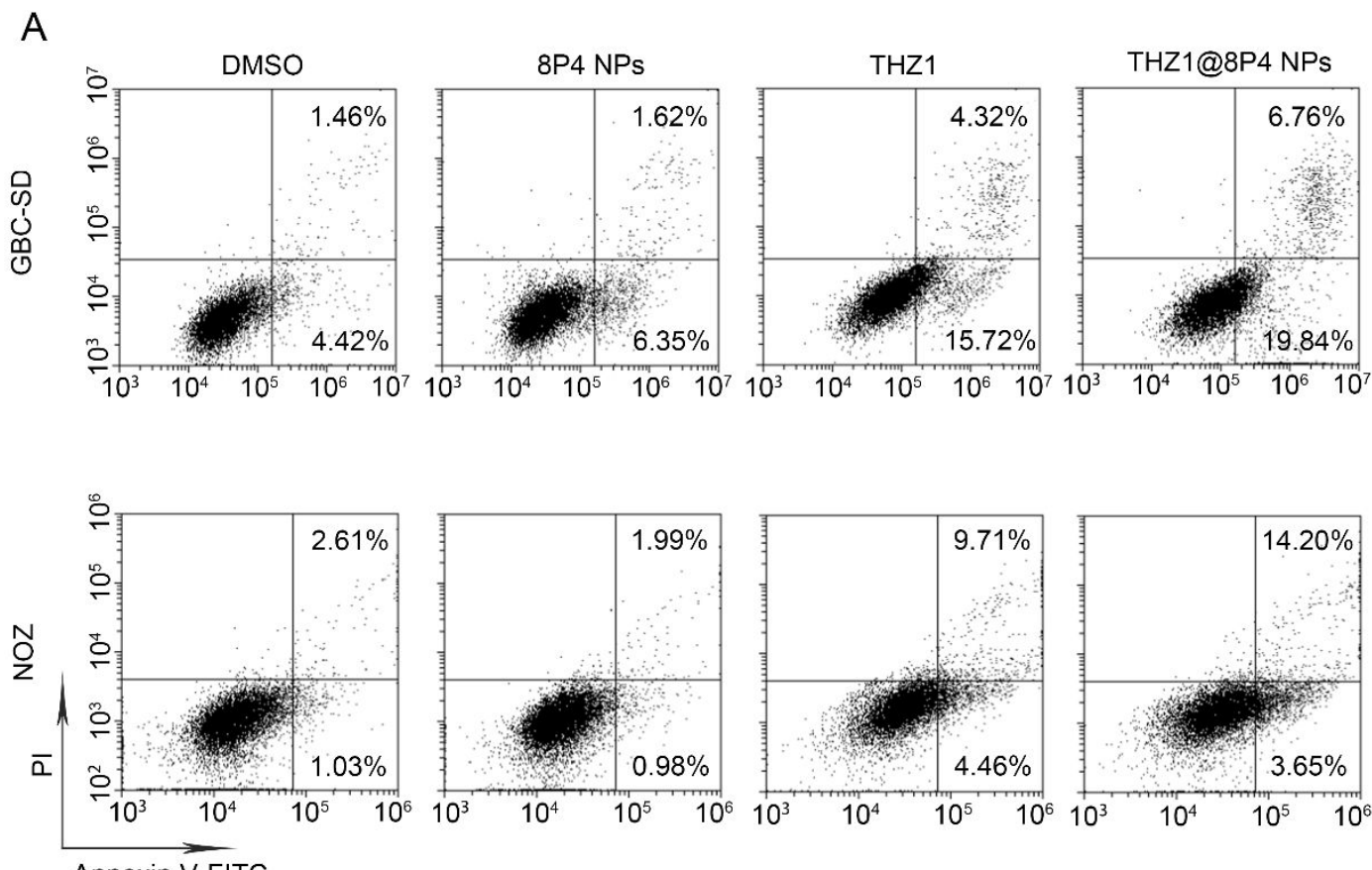

Annexin V-FITC

B
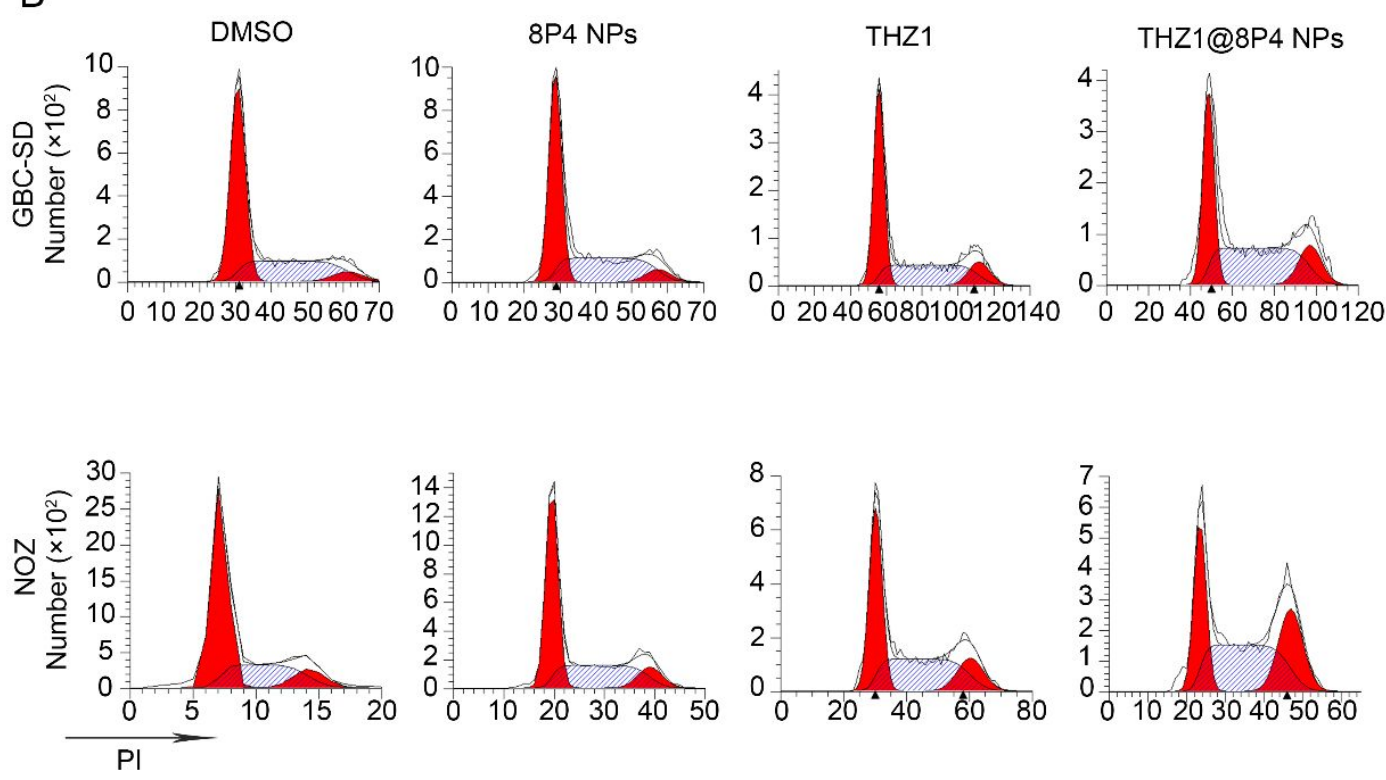

Figure S13. Tumor targeting efficiency of THZ1@8P4 NPs in vitro.

A. Representative flow cytometry data of apoptosis analysis of GBC-SD or NOZ cells upon different treatments (DMSO, 8P4 NPs, THZ1, or THZ1@8P4 NPs).

B. Representative flow cytometry data of cell cycle analysis of GBC-SD and NOZ cells upon different treatments (DMSO, 8P4 NPs, THZ1, or THZ1@8P4 NPs). 
A

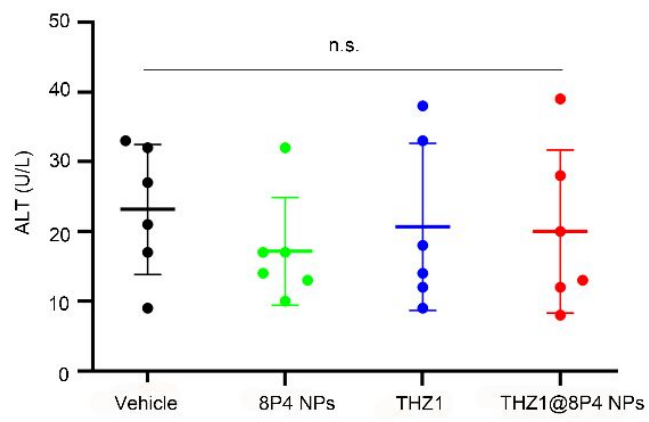

C

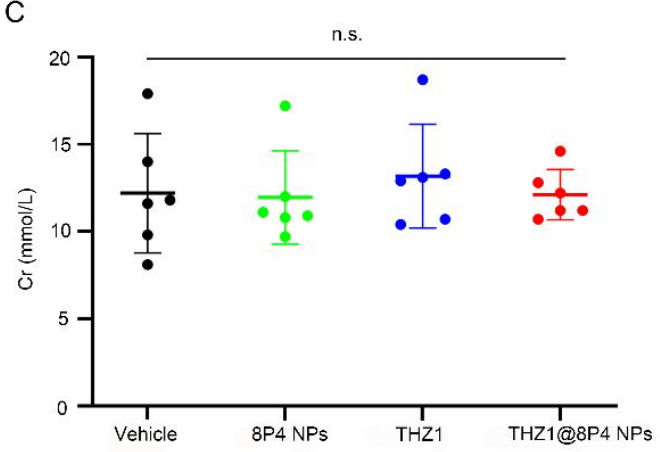

B

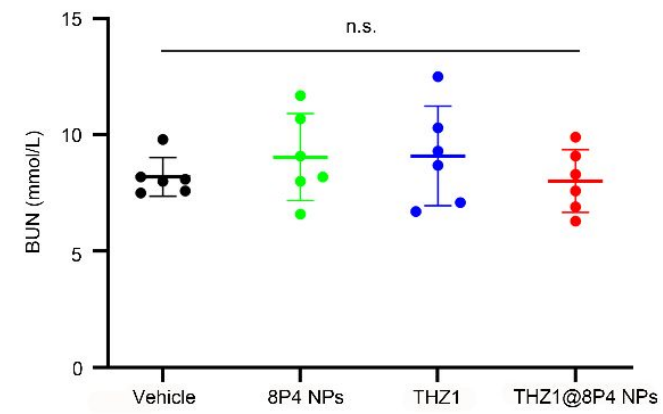

Figure S14. The concentrations of serum alanine aminotransferase (ALT), creatinine (Cr), and blood urea nitrogen (BUN) in different treatment groups.

A. Serum ALT level of the mice $(n=6)$ in different groups (PBS, 8P4 NPs, THZ1, or THZ1@8P4 NPs).

B. Serum BUN level of the mice $(n=6)$ in different groups (PBS, 8P4 NPs, THZ1, or THZ1@8P4 NPs).

C. Serum CR level of the mice $(n=6)$ in different groups (PBS, 8P4 NPs, THZ1, or THZ1@8P4 NPs). 
Supplementary Table1. Sequences of siRNA and primers used for experiments in this study

\begin{tabular}{|c|c|}
\hline Names & Sequences \\
\hline CDK7-siRNA-1-sense & GGACAUAGAUCAGAAGCUA \\
\hline CDK7-siRNA-2-sense & GCUAAGUCAUCCAAAUAUA \\
\hline CDK12-siRNA-1-sense & GCGACAAAGTGGTGTTGTA \\
\hline CDK12-siRNA-2-sense & GAAAGAAGTGGCTCTTACA \\
\hline CDK13-siRNA-1-sense & GCAATATCGTCGAAAGTTA \\
\hline CDK13-siRNA-2-sense & GGAGCAACATGTAGCTTTA \\
\hline$J U N$-siRNA-1-sense & AGAUGGAAACGACCUUCUA \\
\hline$J U N$-siRNA-2-sense & CCAAGAACGUGACAGAUGA \\
\hline FOSL1-siRNA-1-sense & GGCUGCAGCGAGAGAUUGA \\
\hline FOSL1-siRNA-2-sense & GGAGACUGACAAACUGGAA \\
\hline$G A P D H$-primer-F & AGATCATCAGCAATGCCTCCT \\
\hline$G A P D H$-primer-R & TGAGTCCTTCCACGATACCAA \\
\hline$C D K 7$-primer-F & ATGGCTCTGGACGTGAAGTCT \\
\hline$C D K 7$-primer-R & GCGACAATTTGGTTGGTGTTC \\
\hline$J U N$-primer-F & TCCAAGTGCCGAAAAAGGAAG \\
\hline$J U N$-primer-R & CGAGTTCTGAGCTTTCAAGGT \\
\hline FOSL1-primer-F & CAGGCGGAGACTGACAAACTG \\
\hline FOSL1-primer-R & TCCTTCCGGGATTTTGCAGAT \\
\hline
\end{tabular}

